\title{
Formulation and Mathematical Optimization of Controlled Release Calcium Alginate Micro Pellets of Frusemide
}

\author{
Amitava Ghosh and Prithviraj Chakraborty \\ Bengal College of Pharmaceutical Sciences \& Research, Bidhannagar, Durgapur, West Bengal 713212, India \\ Correspondence should be addressed to Prithviraj Chakraborty; prithvirajchakraborty.pc@gmail.com
}

Received 3 April 2013; Revised 21 May 2013; Accepted 27 May 2013

Academic Editor: Chang-Yang Gong

Copyright (C) 2013 A. Ghosh and P. Chakraborty. This is an open access article distributed under the Creative Commons Attribution License, which permits unrestricted use, distribution, and reproduction in any medium, provided the original work is properly cited.

\begin{abstract}
Objective. Frusemide loaded calcium alginate micropellets, an oral microparticulate delivery system, was statistically optimized exhibiting prolonged therapeutic action minimizing its adverse effects. Methods. Ionotropic Gelation technique was adopted employing $3^{2}$ Factorial designs and keeping the entire process free from organic solvents. Physicochemical and the release characteristics of the prepared formulations were studied, keeping variations only in sodium alginate (primary polymer) and Acrycoat E30D (copolymer) dispersion. Result. Sodium alginate was predominant over Acrycoat E30D in all batches. Nonadditives or interaction was observed to be insignificant. Multiple regressions produced second-order polynomial equation, and the predictive results obtained were validated with high degree of correlation. The in vivo study applauded that optimized calcium alginate micropellets of frusemide can produce a much greater diuretic effect over an extended period of 24 hours. Conclusion. This study reveals that the potential of a single dose of the mathematically optimized micro pellets of frusemide formulation is sufficient in the management of peripheral edema and ascites in congestive heart failure and as well in the treatment of chronic hypertension, leading to better patient compliance, and can be produced with minimum experimentation and time, proving far more cost-effective formulation than the conventional methods of formulating dosage forms.
\end{abstract}

\section{Introduction}

The development of pharmaceutical formulation depends on several factors and process parameters. The response variables related to effectiveness, safety, and usefulness must be optimized through a factorial relationship by combining the casual factors. However, this effort addresses a multiobjective optimization problem since it has to circumvent many difficulties in the quantitative approach, like understanding of the actual relationship between casual factors and individual pharmaceutical responses or the prediction of those formulations that are desirable for as many as possible drug properties [1].

Due to the complex nature of the development of pharmaceutical formulations, some computer based optimization techniques have been proposed in the literature. Among them, factorial design (FD) and response surface methodology (RSM) are the most widely used, and several research efforts have adopted either FD followed by an RSM or solely RSM. FD is a technique that contributes to the structure of data collection process. Through a designed experiment, FD is capable of characterizing the relationship between important and unimportant factors. The aim of RSM is utilized to find out the ideal operating conditions for a given system or the manner in which a particular response is affected by a set of variables over some specific regions of interest. The first step in the RSM is to find out a suitable approximation of the true functional relationship between the dependent variable and the set of independent variables (factors) [1]. Based on the principal of design of experiments (DoE), the methodology uses various types of experimental design, generation of polynomial equations, and mapping of the response over the experimental domain to determine the optimum formulation(s) [2-6].

The technique requires minimum experimentation and time, thus proving far more cost-effective formulation than the conventional methods of formulating dosage forms.

The current study aims at developing and optimizing an oral micropellet system of calcium alginate containing 
frusemide (an anthranilic acid derivative and a loop diuretic used in the treatment of congestive heart failure and edema) using RSM, as it is expected to be more productive than the conventional CR systems by virtue of prolongation of drug residence time in GI tract. Computer-aided optimization technique, factorial 2FI Model, was employed to investigate the effect of the primary polymer, sodium alginate (sodium salt of alginic acid), and copolymer, Acrycoat E30D (containing $30 \%$ solids which is prepared by emulsion polymerization and consists of neutral copolymers of ethyl acrylate and methyl methacrylate esters that are insoluble over the entire physiological $\mathrm{pH}$ range), as the two important variables [7], on the nature and performance of the microparticulate drug delivery system.

\section{Materials and Methods}

2.1. Materials. Frusemide was provided ex gratia by Aventis Pharma Ltd. (Ankleshwar, India), Acrycoat E30D was a gift from Corel Pharma (Ahmedabad, India), and sodium alginate was purchased from Loba Chemie, (Mumbai, India). Calcium chloride was purchased from RanChem (India). All other chemicals employed were of analytical grade.

2.2. Experimental Design. In order to optimize the formulation design in producing calcium alginate micropellets of frusemide the effects of the primary polymer, sodium alginate, and copolymer, Acrycoat E30D, on the nature and performance of the micro particulate drug delivery system were studied as two important variables. To get an estimate of the performance of the drug delivery system from the preliminary investigations [7], the following dissolution parameters were considered as responses of the variables.

(i) Zero-order release rate constant $-K_{0}(\mathrm{mg} / \mathrm{hr})$.

(ii) Amount of drug released in 2 hours (burst effect)$X_{120}(\mathrm{mg})$.

(iii) Time required for $80 \%$ drug release $-t_{80}(\mathrm{hr})$.

(iv) Peppas Diffusion coefficient- $n$.

From the preliminary in vitro dissolution aspect of the formulations, it has been seen that on a span of overall release of 0-9 hours the release mechanism of the drug followed predominantly zero-order release model [7]. Hence, the zero-order release rate constant $\left(K_{0}\right)$ was selected as viable response to be studied statistically. The values of $K_{0}$ of the nine different formulations were analyzed by 2way ANOVA and linear regression analysis. The regression equation obtained from the analysis was used to predict the value of $K_{0}$ with uninvestigated concentrations of sodium alginate and Acrycoat E30D. Formulations with the said concentrations were then prepared, and the actual $K_{0}$ value obtained was compared with the predicted value. The other responses studied in this investigation were as follows $\left(X_{120}\right)$ the amount in $\mathrm{mg}$ of drug released in 120 minutes or 2 hours was taken into account so as to have an estimate of burst release mechanism and initial therapeutic dose being made available by the formulations so as to elicit fast onset of action, $\left(t_{80}\right)$ the time required for the drug to release $80 \%$ of its actual content gives an indirect estimation of the dissolution efficiency of the formulations as calculations of $100 \%$ release would have been too ideal to study, and the diffusion coefficient factor $(n)$ of Korsmeyer-Peppas equation signifies that the diffusion behaviour of the drug from the polymer matrix follows either Fickian or Non-Fickian mechanism [8]. Statistical optimization was necessary to justify the significance or non significance " $n$ " irrespective of the concentration of the polymers. The design summary was depicted in Table 1.

\subsection{The Formulation Design: Full $3^{2}$ Factorial Design. Micro-} pellets of frusemide were prepared by full $3^{2}$ factorial designs. Only two variables, with variations at three levels, namely, high, medium, and low, were observed by varying the concentrations of Sodium alginate and Acrycoat E30D. Hence, $3^{2}$ model designs were selected. High, medium, and low levels of sodium alginate were $4 \% \mathrm{w} / \mathrm{v}, 2 \% \mathrm{w} / \mathrm{v}$, and $1 \% \mathrm{w} / \mathrm{v}$, respectively, and that for Acrycoat E30D the levels were $4 \% \mathrm{w} / \mathrm{w}, 2 \% \mathrm{w} / \mathrm{w}$, and $0 \% \mathrm{w} / \mathrm{w}$. All the other parameters were kept unchanged from its optimized level. The formulation design is tabulated in Table 2.

2.4. Preparations of Frusemide Loaded Calcium Alginate Micropellets. A flow sheet of the entire methodology for the preparation of frusemide loaded calcium alginate micropellets was shown in Figure 1.

2.5. Particle Size Analysis. A sample of fully dried micropellets $(10 \mathrm{~g})$ was placed on the top sieve no. 16 . The set of Indian Pharmacopoeia standard [9] sieves were arranged in the order of nos. 16, 22, 30 of aperture size 1000, 710, and $500 \mu \mathrm{m}$, respectively. The entire set was shaken for 5 minutes in a sieve shaker. Pellets retained in each sieve were weighed, and the percentage weight retained against various sieve size was recorded. The average particle size was calculated from the following formula [8]:

$$
d_{\text {average }}=\frac{\sum(n \times d)}{\sum n},
$$

where $n$ is the frequency weight and $d$ is the mean size. The latter was calculated by taking the average of the nominal mesh size of two corresponding sieves. The average diameter and the mode of distribution were calculated mathematically for six times, and the results were tabulated in Table 3.

2.6. Rheological Study. To assess the flow properties of the prepared micropellets measurement of angle of repose method [10] was employed. The angle of repose was calculated (Table 3 ) by measuring the height $(h)$ of the pile and the radius of the base $(r)$ with a ruler. The results obtained are recorded in triplicate.

2.7. Determination of Drug Content and Drug Entrapment Efficiency (DEE) of the Frusemide Loaded Calcium Alginate Micropellets. About $100 \mathrm{mg}$ of micropellets (no. 30 sizes) was 


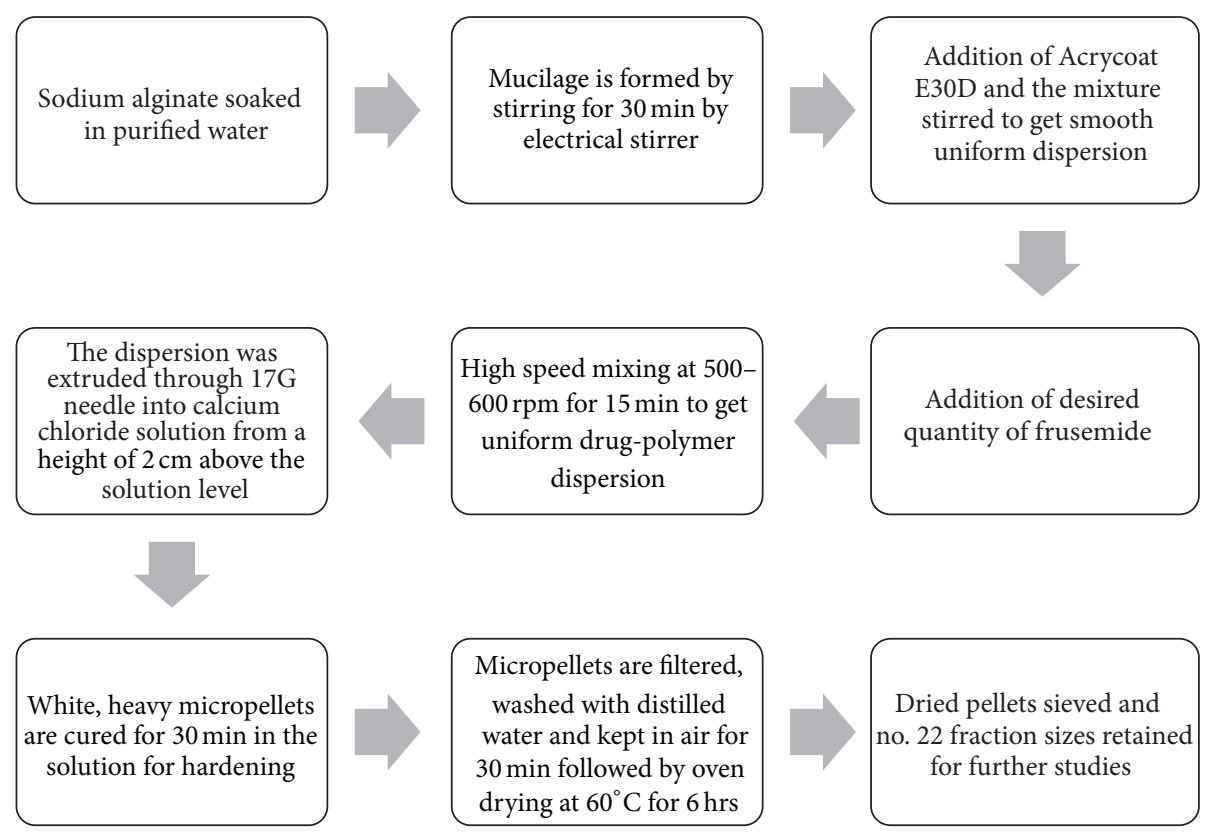

FIGURE 1: Flow sheet of the ionotropic gelation method employed for the preparation of frusemide loaded calcium alginate micropellets.

TABLE 1: Design summary of experimental design.

(a)

\begin{tabular}{llcccc}
\hline Study type & Initial design & Center points & Design model & Runs & Blocks \\
\hline Factorial & Full Factorial & 0 & 2FI & 9 & No Blocks \\
\hline
\end{tabular}

(b)

\begin{tabular}{lcccccc}
\hline Factor & Name & Units & Type & Low Actual & High Actual & Levels \\
\hline$A$ & Alginate & $\% w / w$ & Categoric & $1 \%$ & $4 \%$ & 3 \\
$B$ & Acrycoat E30D & $\% w / w$ & Categoric & $0 \%$ & $4 \%$ & 3 \\
\hline
\end{tabular}

(c)

\begin{tabular}{lccccccccc}
\hline Response & Name & Units & Observn. & Analysis & Min. & Max. & Mean & SD & Ratio \\
\hline Y1 & $K_{0}$ & $\mathrm{mg} / \mathrm{hr}$ & 9 & Factorial & 8.89 & 11.47 & 10.64 & 0.82 & 1.29 \\
Y2 & $X_{120}$ & $\mathrm{mg}$ & 9 & Factorial & 8.00 & 37.34 & 22.51 & 10.7 & 4.67 \\
Y3 & $t_{80}$ & $\mathrm{hr}$ & 9 & Factorial & 4.50 & 9.30 & 7.12 & 1.47 & 2.07 \\
Y4 & $n$ & & 9 & Factorial & 0.60 & 1.79 & 1.01 & 0.37 & 3.00 \\
\hline
\end{tabular}

The design matrix Evaluation for factorial 2FI model.

Degrees of freedom $(\mathrm{dF})$ for evaluation, model: 8 , residuals: 0 , lack of fit: 0 , pure error: 0 , and total: 9 .

accurately weighed and dissolved in $25 \mathrm{~mL}$ of phosphate buffer ( $\mathrm{pH}$ 7.4) and kept overnight. An aliquot from the filtrate was analysed spectrophotometrically, after suitable dilution, using SHIMADZU UV-VIS spectrophotometer, at $277.5 \mathrm{~nm}$. Reliability of the method [11] was judged by conducting recovery analysis using known amount of drug with or without polymer. Recovery was found to be averaged at $100 \pm 0.89 \%$. Drug content of every batch was determined in triplicate for (no. 30) size range of micropellets, and the mean \pm SD was calculated. Drug entrapment efficiency (DEE) was calculated (Table 3 ) using the formula

$$
\% \mathrm{DEE}=\left(\frac{\text { Actual drug content }}{\text { Theoretical drug content }}\right) \times 100
$$

2.8. Loose Surface Crystal (LSC) Study. $100 \mathrm{mg}$ of micro pellets (no. 30 sizes) was suspended in $100 \mathrm{~mL}$ of phosphate buffer ( $\mathrm{pH}$ 6.8), as the dissolution media. The samples were shaken vigorously for $15 \mathrm{~min}$ in a mechanical shaker. The amount of drug leached out from the surface was analysed spectrophotometrically, after suitable dilution, using SHIMADZU UV-VIS spectrophotometer at $277.5 \mathrm{~nm}$. Percentage of drug present loosely on the surface of the micropellets was obtained (Table 3) using following equations [12].

(i) \%LSC with respect to weight of micropellets = amount of drug $(\mathrm{mg})$ released after $15 \mathrm{~min} /$ total weight of micropellets used in the experiment $\times 100$. 
TABLE 2: Full $3^{2}$ factorial design for the formulation of frusemide loaded calcium alginate micropellets.

\begin{tabular}{|c|c|c|}
\hline $\begin{array}{l}\text { Batch } \\
\text { no./formulation } \\
\text { code }\end{array}$ & $\begin{array}{l}\text { Sodium } \\
\text { alginate }\end{array}$ & Acrycoat E30D \\
\hline $\mathrm{F} 1$ & - & - \\
\hline $\mathrm{F} 2$ & - & 0 \\
\hline F3 & - & + \\
\hline $\mathrm{F} 4$ & 0 & - \\
\hline F5 & 0 & 0 \\
\hline F6 & 0 & + \\
\hline F7 & + & - \\
\hline F8 & + & 0 \\
\hline F9 & + & + \\
\hline Level & $\begin{array}{l}\text { Sodium } \\
\text { alginate } \\
(\% \mathrm{w} / \mathrm{w})\end{array}$ & $\begin{array}{c}\text { Acrycoat E30D } \\
(\% \mathrm{w} / \mathrm{w})\end{array}$ \\
\hline+ & 4.0 & 4.0 \\
\hline 0 & 2.0 & 2.0 \\
\hline- & 1.0 & 0.0 \\
\hline
\end{tabular}

concentrations $-30 \% \mathrm{w} / \mathrm{w}$.

(ii) \%LSC with respect to entrapped drug = amount of drug (mg) released after $15 \mathrm{~min} / \mathrm{drug}$ content of micropellets used in the experiment $\times 100$.

2.9. Disintegration Study. Disintegration study was performed in $0.1 \mathrm{M}$ hydrochloric acid and USP phosphate buffer pH 6.8 separately in a rotating bottle apparatus [11]. 5 Micropellets of a fixed size fraction were rotated in $50 \mathrm{~mL}$ of the liquid medium in glass vial at $37^{\circ} \mathrm{C}$ at $30 \mathrm{rpm}$ for 2 hours. Tests were performed in triplicate. Disintegration time (min) was observed (Table 3) when the micropellets were swelled and finally disintegrated and dispersed in the medium. No swelling occurred in $0.1 \mathrm{M}$ hydrochloric acid over 24 hours.

2.10. Study on Drug: Polymer Interaction Using Infrared (IR) Spectroscopy. The method adopted was Disc Method as per British Pharmacopoeia [13]. The drug and formulation were grounded carefully, spread uniformly in a suitable die, and submitted in vacuo to a pressure of about $800 \mathrm{MPa}\left(8 \mathrm{t} \cdot \mathrm{cm}^{-2}\right)$. Disc samples were analysed in FTIR spectrophotometer (SHIMADZU FTIR-8400S, Japan) over a range of 400$4000 \mathrm{~cm}^{-1}$. Both absorbance $(A)$ and transmittance $(T)$ spectra were recorded.

2.11. Study on Drug: Polymer Interaction Using High Performance Liquid Chromatography (HPLC). The primary objective of the study was to identify any potential interactions or incompatibility among the drug and the polymers used in the formulation. The principle behind this identification was by comparing the retention time of both the standard drug sample and the drug extracted from the micropellets containing all the polymers [14]. The value of $R_{r} \sim 1$ signifies nil or insignificant interaction. $10 \mu \mathrm{L}$ of the sample was injected (HPLC: SHIMADZU LC-20AT/SPD-20A, JAPAN) and detected at a wavelength of $277.5 \mathrm{~nm}$.

2.12. Morphological Study of the Micropellets Using Scanning Electron Microscopy (SEM). Morphological characterization of the micropellets was done by taking scanning electron micrograph in JEOL (Japan), JSM Model 5200 Scanning Electron Microscope. The samples were initially coated to $200 \AA$ thickness with gold-palladium using Pelco Model 3 sputter coater, prior to microscopy.

2.13. In Vitro Drug Release Studies of Frusemide Loaded Calcium Alginate Micropellets. The USP rotating, paddle dissolution rate apparatus (Veego, Mumbai, India), was used to study drug release from the micropellets. The rotation of the paddles was fixed to $50 \mathrm{rpm}$, and temperature was kept at $37 \pm 2^{\circ} \mathrm{C}$ throughout the experiment. At these specified time intervals $(0.5,1,2,3,4,5,6,7,8$, and 9 hrs.), a fixed volume of sample $(10 \mathrm{~mL})$ was withdrawn from the dissolution medium (phosphate buffer of $\mathrm{pH}$ 6.8) and substituted by equal volume of fresh medium. The withdrawn samples were diluted suitably, and the drug contents in the samples were determined by using SHIMADZU UV-VIS 2400 spectrophotometer at $277.5 \mathrm{~nm}$. The tests were performed in triplicate, and mean value was taken for further calculation.

2.14. In Vivo Performance of the Prepared Sustained Release Calcium Alginate Micropellets. To assess the pharmacological (diuretic) activity through in vivo performance of the prepared sustained release calcium alginate micropellets containing frusemide (F9), it was compared with conventional frusemide tablet (LASIX), as standard diuretic agent, after administering it orally to male Wistar rats. The purpose was met by estimating the efficacy of the test formulation (F9) in producing diuresis for more than 8 hours when compared to a standard diuretic agent and a placebo control (normal saline, $0.9 \% \mathrm{w} / \mathrm{v}$ ) using urine analysis data of the animals. Modified Lipschitz $[15,16]$ test model was employed to estimate excretion of water $\left(\mathrm{H}_{2} \mathrm{O}\right)$, sodium $(\mathrm{Na})$, and potassium $(\mathrm{K})$ in test animals after administration of the test formulation and compared with the results obtained from the animals treated with high dose of urea. The entire procedure followed noninvasive method, and necessary permission was obtained from the Institutional Animal Ethics Committee (vide sanction of proposal no. HPI/07/60/IAEC/0004). 3 groups consisting of 5 animals, in each, of Wistar albino rats were kept unfed without water for 15 hour. The test group (Group T) received the test formulation (F9) at a dose of $50 \mathrm{mg} / \mathrm{kg}$ body weight in $5 \mathrm{~mL}$ water orally. Additionally, $5 \mathrm{~mL}$ of normal saline solution per $100 \mathrm{~g}$ body weight was given by gavages. The standard group (Group S) received the standard tablet (LASIX, $40 \mathrm{mg}$ ) admixed, at the same dose of test formulation in normal saline. The control group (Group C) received only $5 \mathrm{~mL}$ of normal saline solution per $100 \mathrm{~g}$ body weight. Excretion of urine was recorded after 5 and 24 hours (Table 8) to have a clear estimation of the duration of the diuretic effect. Sodium and potassium contents in the 
TABLE 3: Evaluation result of physicochemical parameter of frusemide calcium alginate micropellets.

\begin{tabular}{|c|c|c|c|c|c|c|c|}
\hline $\begin{array}{l}\text { Formulation } \\
\text { code }\end{array}$ & $\begin{array}{c}\text { Mean } \\
\text { diameter* } \\
(\mu \mathrm{m} \pm \mathrm{SD})\end{array}$ & $\begin{array}{l}\text { Angle of } \\
\text { repose }(\theta)^{* *}\end{array}$ & $\begin{array}{l}\% \text { Moisture } \\
\text { content }^{* *}\end{array}$ & $\begin{array}{l}\text { Drug entrapment } \\
\text { efficiency }(\%)^{* *}\end{array}$ & $\begin{array}{l}\text { LSC (\%) with } \\
\text { respect to gross wt. } \\
\text { of the micropellets }\end{array}$ & $\begin{array}{l}\text { LSC }(\%) \text { with } \\
\text { respect to entrapped } \\
\text { drug }\end{array}$ & $\begin{array}{l}\text { Disintegration } \\
\text { time }(\min )^{* *}\end{array}$ \\
\hline $\mathrm{F} 1$ & $608.14 \pm 0.39$ & $16.76 \pm 0.54$ & $1.71 \pm 0.81$ & $95.94 \pm 0.63$ & 2.271 & 2.367 & $24 \pm 4.53$ \\
\hline $\mathrm{F} 2$ & $655.90 \pm 1.03$ & $18.06 \pm 0.96$ & $1.59 \pm 0.76$ & $99.02 \pm 0.82$ & 1.943 & 1.962 & $36 \pm 5.21$ \\
\hline F3 & $694.85 \pm 0.72$ & $20.11 \pm 0.88$ & $1.97 \pm 0.32$ & $99.47 \pm 0.91$ & 1.677 & 1.686 & $52 \pm 4.68$ \\
\hline $\mathrm{F} 4$ & $608.16 \pm 0.59$ & $18.32 \pm 0.79$ & $1.48 \pm 0.48$ & $94.48 \pm 0.48$ & 3.353 & 3.549 & $42 \pm 3.85$ \\
\hline F5 & $760.89 \pm 0.51$ & $20.56 \pm 1.03$ & $1.44 \pm 0.56$ & $93.44 \pm 0.56$ & 2.214 & 2.369 & $64 \pm 6.11$ \\
\hline F6 & $782.78 \pm 0.36$ & $21.24 \pm 1.97$ & $2.23 \pm 0.68$ & $91.23 \pm 0.68$ & 1.429 & 1.567 & $97 \pm 4.37$ \\
\hline F7 & $632.1 \pm 0.73$ & $19.52 \pm 1.21$ & $1.67 \pm 0.33$ & $96.21 \pm 0.37$ & 1.882 & 1.956 & $73 \pm 5.24$ \\
\hline F8 & $693.36 \pm 0.56$ & $21.39 \pm 1.07$ & $1.42 \pm 0.54$ & $97.76 \pm 0.56$ & 0.913 & 0.729 & $115 \pm 5.98$ \\
\hline F9 & $841.65 \pm 0.48$ & $22.56 \pm 0.77$ & $2.32 \pm 0.64$ & $98.37 \pm 0.77$ & 0.594 & 0.604 & $>120$ \\
\hline
\end{tabular}

${ }^{*}$ Results shown are "mean $\pm \mathrm{SD}$," $n=6$ for mean diameter; signifies value $<0.01 \%$. ${ }^{* *}$ Results shown are "mean $\pm \mathrm{SD}, " n=3$.

collected urine were determined (Table 9, Figure 8) by using Flame Photometer, Model Type 121, Systronics, India.

The Lipschitz quotients for urine volume and sodium ion excretion for both standard and test samples were tabulated in Table 10.

\section{Result and Discussion}

3.1. Micro Pellet Morphology and Particle Size Analysis. After drying, the moist micropellets were kept in an oven for 6 hours at $60^{\circ} \mathrm{C}$, and the resultant dry micropellets were physically evaluated which were discoid in shape rather than purely spherical. With the increase in polymer load, namely, the formulations F7, F8, and F9, more sphericity were obtained. The micropellets containing only sodium alginate (formulations F1, F4, and F7) were off-white in colour whereas with the addition of Acrycoat E30D light yellowish micropellets resulted. From the particle size analysis of frusemide loaded calcium alginate micropellets as observed form Table 3, it is evident that the size range of all the formulations ranged between $600 \mu \mathrm{m}$ and $850 \mu \mathrm{m}$. According to the results of the size range, it was technically proved that the term micropellets for the formulation had been correctly coined. They could also be classified under microspheres as the size range of microspheres ranges $5 \mu \mathrm{m}-1000 \mu \mathrm{m}$. The micropellets of first three formulations having low level $(1 \% \mathrm{w} / \mathrm{v})$ of sodium alginate showed particles of least size range compared to the remaining six, though formulations F7 and F8 showed similar results. Formulations F3, F6, and F9 which contain high level (4\% w/w) of Acrycoat E30D showed steady increase in particle size along with different levels of sodium alginate.

3.2. Rheology of Micropellets of Frusemide. All the formulations showed angle of repose in a range $16^{\circ}-23^{\circ}$. On interpreting the result with the values of Table 3 , it could be inferred that all formulations of frusemide micropellets were free flowing and while tableting them or encapsulating in capsule shell, and lubricants need not to be added.
3.3. Drug Content and Drug Entrapment Efficiency (DEE). From the results presented in Table 3, it was observed that ionotropic gelation technique produced micropellets of high encapsulation efficiency. The DEE value varies within a very short range from 91 to $99 \%$ among all the nine formulations indicating very small amount of drug loss during the process. The formulations F1, F2, and F3 with low level of sodium alginate $(1 \% \mathrm{w} / \mathrm{v})$ showed marginally higher entrapment when compared to the other two levels. This may be explained by the fact that at higher concentration sodium alginate forms a rigid matrix with Calcium Chloride preventing incorporation of drug during the curing period in the calcium chloride solution. However the study evidenced that sodium alginate and Acrycoat E30D do not have much significant effect in the drug content of the formulations, since the drug contents were within $\pm 5 \%$ of the labelled potency of the drug in all the formulations.

3.4. Loose Surface Crystal (LSC) Analysis. The values of LSC were an important parameter giving an indication of the amount of drug available on the surface of the micropellets for immediate absorption and to elicit quick onset of action. The data presented in Table 3 showed that very small amount of drug ranging from $0.604 \%$ to $3.549 \%$ with respect to total entrapped drug is available loosely on the surface of the micropellets. It was also observed that with the increase in the concentration of Acrycoat E30D, there was a gradual decrease in the value of \%LSC. The formulations prepared without secondary polymer (Acrycoat E30D), namely, F1, F4, and F7, reflected much higher amount of drug loosely available on the surface.

3.5. Disintegration Study. The results of disintegration study revealed that the ionic character of the polysaccharides showed pH-dependent disintegration of the micropellets. In calcium alginate pellets, the carboxyl groups in the alginate moiety got ionized in the higher $\mathrm{pH}$, thereby repelling each other. As a result, fluid was drawn inside the pellets producing swelling, and ultimately the micropellets busted out. With the 
TABLE 4: Summary of ANOVA for the response parameters.

\begin{tabular}{|c|c|c|c|c|c|c|}
\hline Source & Sum of squares & Degree of freedom dF & Mean square & $F$ value & $\begin{array}{c}P \text { value } \\
\text { prob. }>F\end{array}$ & Effect \\
\hline \multicolumn{7}{|c|}{ For “ $K_{0}$ ” } \\
\hline Model & 5.91 & 5 & 1.18 & 40.21 & 0.0060 & \multirow{8}{*}{ significant } \\
\hline$A:$ alginate $\% \mathrm{w} / \mathrm{w}$ & 3.13 & 1 & 3.13 & 106.59 & 0.0019 & \\
\hline$B$ : acrycoat E30D \%w/w & 0.83 & 1 & 0.84 & 28.70 & 0.0127 & \\
\hline$A B$ & 0.23 & 1 & 0.23 & 7.77 & 0.0685 & \\
\hline$A^{2}$ & 0.97 & 1 & 0.97 & 32.96 & 0.0105 & \\
\hline$B^{2}$ & $1.875 E-004$ & 1 & $1.875 E-004$ & $6.379 E-003$ & 0.9414 & \\
\hline Residual & 0.088 & 3 & 0.029 & & & \\
\hline Correction total & 6 & 8 & & & & \\
\hline \multicolumn{6}{|c|}{ For “ $X_{120} "$} & \multirow{9}{*}{ significant } \\
\hline Model & 1012.2 & 5 & 202.44 & 33.26 & 0.0079 & \\
\hline$A:$ alginate $\% \mathrm{w} / \mathrm{w}$ & 558.39 & 1 & 558.39 & 91.74 & 0.0024 & \\
\hline$B$ : acrycoat E30D \%w/w & 70.4 & 1 & 70.4 & 11.57 & 0.0424 & \\
\hline$A B$ & 43.53 & 1 & 43.53 & 7.15 & 0.0754 & \\
\hline$A^{2}$ & 517.97 & 1 & 517.97 & 85.10 & 0.0027 & \\
\hline$B^{2}$ & 5.74 & 1 & 5.74 & 0.94 & 0.4032 & \\
\hline Residual & 18.26 & 3 & 6.09 & & & \\
\hline Correction total & 1030.46 & 8 & & & & \\
\hline \multicolumn{6}{|c|}{ For " $t_{80}$ " } & \multirow{9}{*}{ significant } \\
\hline Model & 19.15 & 5 & 3.83 & 38.12 & 0.0065 & \\
\hline$A$ : alginate $\% \mathrm{w} / \mathrm{w}$ & 16.34 & 1 & 16.34 & 162.55 & 0.0010 & \\
\hline$B$ : acrycoat E30D \%w/w & 1.99 & 1 & 1.99 & 19.76 & 0.0212 & \\
\hline$A B$ & $2.176 E-003$ & 1 & $2.176 E-003$ & 0.03 & 0.8743 & \\
\hline$A^{2}$ & 2.63 & 1 & 2.63 & 26.12 & 0.0145 & \\
\hline$B^{2}$ & 0.014 & 1 & 0.014 & 0.14 & 0.7348 & \\
\hline Residual & 0.30 & 3 & 0.10 & & & \\
\hline Correction total & 19.46 & 8 & & & & \\
\hline \multicolumn{6}{|c|}{ For “ $n "$} & \multirow{9}{*}{ Not significant } \\
\hline Model & 1.11 & 5 & 0.22 & 5.56 & 0.0943 & \\
\hline$A$ : alginate $\% \mathrm{w} / \mathrm{w}$ & 0.33 & 1 & 0.33 & 8.38 & 0.0627 & \\
\hline$B:$ acrycoat E30D \%w/w & 0.17 & 1 & 0.17 & 4.15 & 0.1345 & \\
\hline$A B$ & 0.013 & 1 & 0.013 & 0.33 & 0.6043 & \\
\hline$A^{2}$ & 0.73 & 1 & 0.73 & 18.43 & 0.0232 & \\
\hline$B^{2}$ & 0.025 & 1 & 0.025 & 0.63 & 0.4864 & \\
\hline Residual & 0.12 & 3 & 0.04 & & & \\
\hline Correction total & 1.23 & 8 & & & & \\
\hline
\end{tabular}

$A$ and $B$ represent the main effects (factors); $A^{2}$ and $B^{2}$ are the quadratic effect; $A B$ is the interaction effect.

TABLE 5: Correlation coefficients $\left(R^{2}\right)$ of different plots for overall $(0-9 \mathrm{hr})$ release kinetics of frusemide from prepared micropellets.

\begin{tabular}{lccccccrrrr}
\hline \multirow{2}{*}{ Kinetic models } & \multicolumn{3}{c}{ Level $(-1)$} & \multicolumn{3}{c}{ Correlation coefficients $\left(R^{2}\right.$ values $)$} & \multicolumn{3}{c}{ Level $(+1)$} \\
& F1 & F2 & F3 & F4 & F5 & F6 & F7 & F8 \\
\hline Zero order & 0.8091 & 0.8749 & 0.8949 & 0.9918 & 0.9931 & 0.9397 & 0.9918 & 0.9945 & 0.9945 \\
First order & 0.9240 & 0.9824 & 0.8916 & 0.8678 & 0.8265 & 0.8531 & 0.8328 & 0.8933 & 0.9498 \\
Higuchi & 0.9003 & 0.9495 & 0.9599 & 0.9653 & 0.9638 & 0.8666 & 0.9750 & 0.9644 & 0.9606 \\
Hixson-Crowell & 0.9400 & 0.9819 & 0.9911 & 0.9473 & 0.9314 & 0.9025 & 0.9303 & 0.9485 & 0.9756 \\
\hline
\end{tabular}


TABLE 6: Independent formulation variables and their responses.

\begin{tabular}{|c|c|c|c|c|c|c|}
\hline Formulation code & Sodium alginate conc. $\%(w / w)$ & $\begin{array}{c}\text { Acrycoat E30D } \\
\text { conc. } \%(w / w)\end{array}$ & $K_{0}(\mathrm{mg} / \mathrm{hr})$ & $X_{120}(\mathrm{mg})$ & $t_{80}(\mathrm{hr})$ & $n$ \\
\hline $\mathrm{F} 1$ & 1 & 0 & 10.865 & 34.95 & 4.5 & 1.7429 \\
\hline $\mathrm{F} 2$ & 1 & 2 & 10.209 & 37.34 & 5.2 & 1.7309 \\
\hline F3 & 1 & 4 & 10.299 & 37.341 & 6.1 & 1.4378 \\
\hline $\mathrm{F} 4$ & 2 & 0 & 9.3247 & 16.988 & 7.2 & 1.8142 \\
\hline F5 & 2 & 2 & 9.0388 & 16.183 & 7.6 & 2.3807 \\
\hline F6 & 2 & 4 & 7.9428 & 8.001 & 7.8 & 1.8064 \\
\hline F7 & 4 & 0 & 7.5642 & 23.173 & 8 & 1.6173 \\
\hline F8 & 4 & 2 & 6.9212 & 17.382 & 8.4 & 1.6074 \\
\hline F9 & 4 & 4 & 6.1069 & 11.194 & 9.3 & 1.5608 \\
\hline
\end{tabular}

TABLE 7: Korsmeyer-Peppas model fitting release rate constants $\left(K_{\mathrm{KP}}\right)$, correlation coefficient $\left(R^{2}\right)$, and release exponent $(n)$ of frusemide from micropellets with different levels of alginate level $(-1,0$, and +1$)$.

\begin{tabular}{|c|c|c|c|c|c|c|c|c|c|}
\hline \multirow{2}{*}{$\begin{array}{l}\text { Korsmeyer-Peppas model } \\
\text { Formulation code }\end{array}$} & \multicolumn{3}{|c|}{ Overall release $(0-9 \mathrm{hr})$} & \multicolumn{3}{|c|}{ PHASE I (0-2 hr) } & \multicolumn{3}{|c|}{ PHASE II (2-9 hr) } \\
\hline & $K_{\mathrm{KP}}$ & $R^{2}$ & $n$ & $K_{\mathrm{KP}} \mathrm{I}$ & $R^{2} \mathrm{I}$ & $n \mathrm{I}$ & $K_{\mathrm{KP}} \mathrm{II}$ & $R^{2} \mathrm{II}$ & $n$ II \\
\hline F1 & 0.6731 & 0.7589 & 1.7429 & 0.7173 & 0.8535 & 3.6857 & 1.4996 & 0.7718 & 0.5952 \\
\hline $\mathrm{F} 2$ & 0.6529 & 0.7663 & 1.7309 & 0.7107 & 0.8682 & 3.7106 & 1.4664 & 0.8925 & 0.6015 \\
\hline F3 & 0.8685 & 0.7749 & 1.4378 & 0.9114 & 0.8359 & 2.96 & 1.4686 & 0.9026 & 0.6005 \\
\hline $\mathrm{F} 4$ & 0.4384 & 0.8909 & 1.8142 & 0.4954 & 0.895 & 3.1443 & 0.9029 & 0.9924 & 1.1637 \\
\hline F5 & 0.0197 & 0.7984 & 2.3807 & 0.1278 & 0.8487 & 4.8791 & 0.8831 & 0.9935 & 1.1705 \\
\hline F6 & 0.3049 & 0.9127 & 1.8064 & 0.3878 & 0.7992 & 2.5957 & 0.3002 & 0.9606 & 1.7854 \\
\hline F7 & 0.567 & 0.9004 & 1.6173 & 0.6205 & 0.9558 & 2.8874 & 1.0778 & 0.9844 & 0.9125 \\
\hline F8 & 0.5268 & 0.9177 & 1.6074 & 0.5699 & 0.9341 & 2.6683 & 0.9295 & 0.995 & 1.0477 \\
\hline F9 & 0.4982 & 0.969 & 1.5608 & 0.5086 & 0.9527 & 2.0875 & 0.719 & 0.9928 & 1.2522 \\
\hline
\end{tabular}

TABLE 8: Lipschitz test values of the collected urine sample.

\begin{tabular}{|c|c|c|c|c|c|c|c|c|}
\hline \multirow{2}{*}{ Sl. no. } & \multirow{2}{*}{ Group } & \multirow{2}{*}{ Treatment } & \multicolumn{2}{|c|}{$\begin{array}{l}\text { Mean volume of urine } \\
\text { collected }(\mathrm{mL})\end{array}$} & \multicolumn{2}{|c|}{$\begin{array}{l}\text { Lipschitz value } \\
\text { (T or S/C) }\end{array}$} & \multicolumn{2}{|c|}{$\begin{array}{l}\text { \% Increase in Volume of Urine } \\
\quad((\mathrm{T} \text { or } \mathrm{S}-\mathrm{C}) / \mathrm{C}) \times 100\end{array}$} \\
\hline & & & 5 th hour (mL) & 24th hour (mL) & 5th hour & 24th hour & 5 th hour $(\%)$ & 24th hour (\%) \\
\hline \multicolumn{9}{|l|}{1} \\
\hline 2 & \multirow{4}{*}{ Control (C) } & \multirow{4}{*}{$\begin{array}{c}\text { Normal saline } \\
5 \mathrm{~mL} / 100 \mathrm{~g} \\
\text { body wt. }\end{array}$} & \multirow{4}{*}{$1.8 \pm 0.92$} & \multirow{4}{*}{$4.8 \pm 1.29$} & \multirow{4}{*}{1.00} & \multirow{4}{*}{1.00} & \multirow{4}{*}{-} & \multirow{4}{*}{-} \\
\hline 3 & & & & & & & & \\
\hline 4 & & & & & & & & \\
\hline 5 & & & & & & & & \\
\hline \multicolumn{9}{|l|}{6} \\
\hline 7 & \multirow{4}{*}{ Standard (S) } & & \multirow{4}{*}{$7.2 \pm 1.37$} & \multirow{4}{*}{$22.2 \pm 3.61$} & \multirow{4}{*}{4.00} & \multirow{4}{*}{4.63} & \multirow{4}{*}{300.0} & \multirow{4}{*}{444.5} \\
\hline 8 & & frusemide & & & & & & \\
\hline 9 & & 50 mg/kg p.o. & & & & & & \\
\hline \multicolumn{2}{|l|}{10} & & & & & & & \\
\hline 11 & \multirow{5}{*}{ Test (T) } & & \multirow{5}{*}{$9.8 \pm 2.06$} & \multirow{5}{*}{$33.7 \pm 4.11$} & \multirow{5}{*}{5.45} & \multirow{5}{*}{7.02} & \multirow{5}{*}{362.5} & \\
\hline 12 & & Frusemide & & & & & & \multirow{4}{*}{$602.1^{*}$} \\
\hline 13 & & micropellets & & & & & & \\
\hline 14 & & 50 mg/kg p.o. & & & & & & \\
\hline 15 & & & & & & & & \\
\hline
\end{tabular}

Values are expressed \pm SEM

“*”Indicates $(P<0.05)$. 
TABLE 9: Flame photometry mean readings of sodium and potassium ions in urine sample from Groups C, S, and T after 5 and 24 hours.

\begin{tabular}{|c|c|c|c|c|c|c|}
\hline \multirow{2}{*}{ Sl. no. } & \multirow{2}{*}{ Group } & \multirow{2}{*}{ Treatment } & \multicolumn{2}{|c|}{$\mathrm{Na}+$ ion } & \multicolumn{2}{|c|}{$\mathrm{K}+$ ion } \\
\hline & & & 5th hour & 24th hour & 5th hour & 24th hour \\
\hline 1 & & & & & & \\
\hline $\begin{array}{l}2 \\
3 \\
4 \\
5 \\
\end{array}$ & $\begin{array}{l}\text { Control } \\
\text { (C) }\end{array}$ & $\begin{array}{c}\text { Normal saline } \\
5 \mathrm{~mL} / 100 \mathrm{~g} \text { body wt. }\end{array}$ & 24 & 28 & 21 & 11 \\
\hline $\begin{array}{l}6 \\
7 \\
8 \\
9 \\
10\end{array}$ & $\begin{array}{l}\text { Standard } \\
\quad(\mathrm{S})\end{array}$ & $\begin{array}{c}\text { Pure frusemide } \\
50 \mathrm{mg} / \mathrm{kg} \\
\text { p.o. }\end{array}$ & 69 & 44 & 25 & 14 \\
\hline $\begin{array}{l}11 \\
12 \\
13 \\
14 \\
15\end{array}$ & $\begin{array}{l}\text { Test } \\
(\mathrm{T})\end{array}$ & $\begin{array}{c}\text { Frusemide } \\
\text { micropellets } \\
50 \mathrm{mg} / \mathrm{kg} \text { p.o. }\end{array}$ & 74 & $67^{*}$ & 30 & $27^{*}$ \\
\hline
\end{tabular}

Values are expressed \pm SEM

“*”Indicates $(P<0.05), n=5$.

TABLE 10: Results of the in vivo parameters studied for both standard (S) and test (T) samples after 5 and 24 hours.

\begin{tabular}{|c|c|c|c|c|c|}
\hline \multirow[t]{2}{*}{ Sl. no. } & \multirow[t]{2}{*}{ Parameter } & \multicolumn{2}{|c|}{ Standard sample (Lasix tablet) } & \multicolumn{2}{|c|}{$\begin{array}{c}\text { Test sample } \\
\text { micropellets (F9) }\end{array}$} \\
\hline & & 5th hour & 24th hour & 5th hour & 24th hour \\
\hline 1 & Lipschitz quotient for urine volume & 4.00 & 4.63 & 5.45 & $7.02^{*}$ \\
\hline 2 & $\%$ Increase in volume of collected urine & 300.0 & 444.5 & 362.5 & $602.1^{*}$ \\
\hline 3 & Lipschitz quotient for $\mathrm{Na}+$ excretion & 5.78 & 2.17 & 6.31 & $4.00^{*}$ \\
\hline 4 & Lipschitz quotient for $\mathrm{K}+$ excretion & 1.27 & 1.61 & 1.60 & 4.26 \\
\hline
\end{tabular}

${ }^{*}$ Indicates $(P<0.05) n=5$.

increase in the proportion of polymer and copolymer (F6 to F9) the disintegration time was delayed, as evidenced from Table 3, due to dense network formation which hindered withdrawal of fluid, hence swelling of the pellets. Formulation F9 showed exceptionally high $(>2 \mathrm{hr}$ ) disintegration time extended beyond the testing time $(2 \mathrm{hr})$ and hence could not be recorded. On keeping this particular formulation for overnight, it was found to be disintegrated and dispersed in the medium. The data obtained also had given an indication of the sustained effect produced by the polymers in releasing the drug in the dissolution medium.

3.6. FTIR Analysis of Frusemide Micropellets. The IR spectra of the materials obtained were presented in Figure 2. From the infrared spectra it was clearly evident that there were no interactions of the drug, frusemide, with the excipients used, namely, sodium alginate and Acrycoat E30D. The main peaks in the spectrum of the drug frusemide like 1143.83 and $1323.21 / \mathrm{cm}$ for $\mathrm{S}=\mathrm{O}$ bond, $1674.27 / \mathrm{cm}$ for $\mathrm{C}=\mathrm{O}$ bond, $3487.42 / \mathrm{cm}$ for $\mathrm{N}-\mathrm{S}$ bond, and 582 for $\mathrm{C}-\mathrm{Cl}$ bond remained undisturbed in the final formulation. This had proven the fact that there was no potential incompatibility of the drug with all the polymers used in the formulations. Hence, the formula for preparing frusemide loaded calcium alginate microspheres could be reproduced in the industrial scale without any apprehension of possible drug-polymer interactions.

3.7. Drug-Polymer Interaction Analysis by HPLC. Chromatograms as represented in Figures 3 and 4, the retention time of both standard sample of pure frusemide and test sample containing Frusemide and polymers was found to be very close and the value of $R_{r} \sim 1$, signifying no detectable interaction among the drug, frusemide, and the polymers such as calcium alginate and Acrycoat E30D which were present in the formulations. This conclusion were further augments the results obtained from FTIR study.

3.8. Scanning Electron Microscopy of Frusemide Micropellets. The scanning electron micrograph of the final sets of micropellets presented in Figure 5 showed that all the formulations produced rounded, rough pellets which could be defined to be purely spherical. When studied at higher magnification (350X and 500X) and when the pellets were centrally dissected and the cross-sectional views were captured, the pellets showed dense network of polymers entrapping the drug. The numerous channels and pores visible in the micrograph showed the pathway through which dissolution medium could permeate into the drug-polymer matrix, swell the 


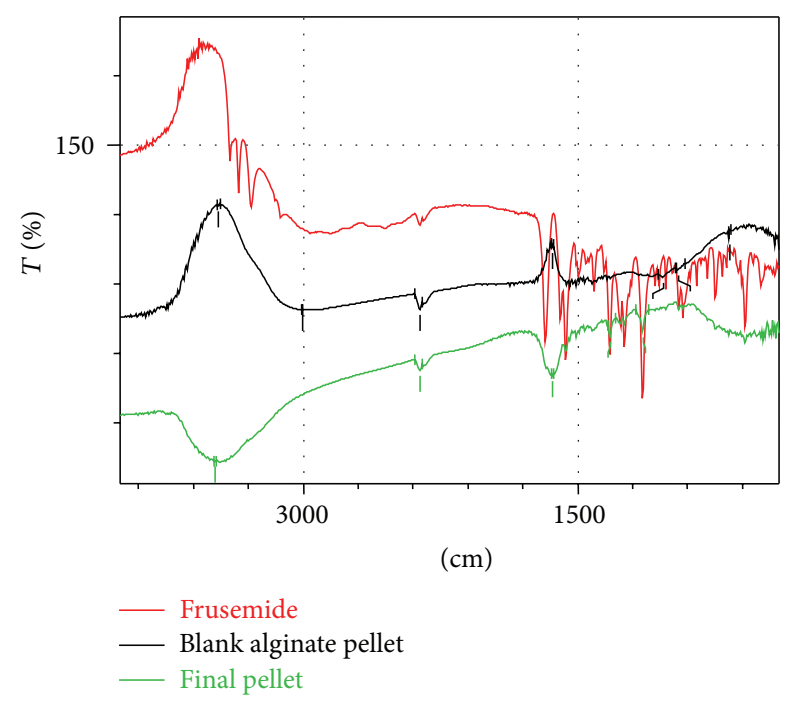

FIGURE 2: IR spectra of frusemide, blank alginate pellets and final micropellets.

polymers, and widen the pore diameter which in turns would help the drug molecule to diffuse from the matrix into the dissolution medium. This fact explained the sustained release nature of the formulation. Presence of free drug on the surface of the pellets supported the logic behind the loose surface crystal study reported.

\subsection{Analysis of In Vitro Drug Release Kinetics and Mechanism.} The in vitro release study unfolded quite an interesting result. Prior to the in vitro studies it was expected that at a particular concentration of sodium alginate, with the increase in concentration of Acrycoat E30D, there would be a decrease in the release rate with the extension of the sustaining release of frusemide from micropellets. In order to analyse the drug release mechanism from the micropellets the following mathematical models were studied, namely, zeroorder model (Figure 6), first-order model, Higuchi model, and Hixson-Crowell model. The correlation coefficient $\left(R^{2}\right)$ was used to compare the model equations depicted in Table 5 and to determine the "best fit" model that explains the release kinetics of the drug from the prepared micropellets. The concentrations of the independent variables and the corresponding-dependent factors obtained from experiments of in vitro dissolution study were enlisted in Table 6.

Among the three batches (F1, F2, and F3) F2 was found to be best fit with first-order kinetics, and for F1 and F3 the $R^{2}$ values of both Hixson-Crowell and first-order kinetics were in close proximity. Hence it could be inferred that at low concentration of sodium alginate the surface area of micropellets decreased exponentially with the time during the dissolution process. During the agitation of the dissolution process there was no stagnation of dissolved, drug and thus proper sink conditions were maintained. In these three formulations the drug released at any time remained proportional to the residual drug inside the dosage form. Further, when the release profile was divided into two phases

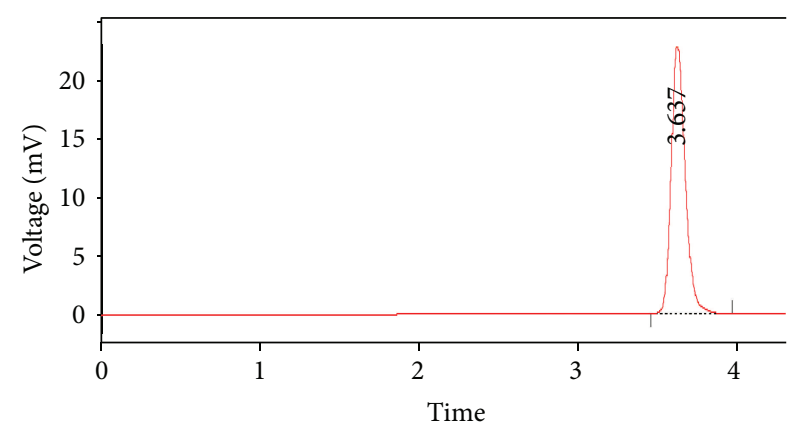

FIGURE 3: Chromatogram of the standard sample of pure frusemide.

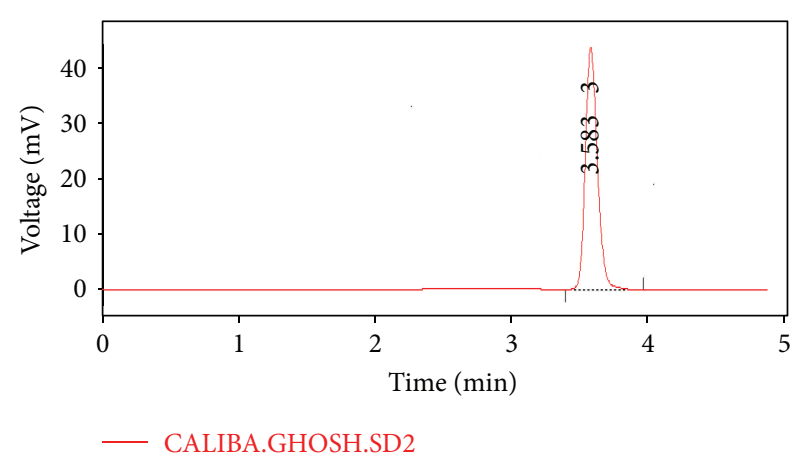

FIGURE 4: Chromatogram of the Test Sample containing Frusemide and Polymers.

to get a more specific release mechanism, it was seen from the $R^{2}$ value (Table 7) that in the phase I the drug release was predominant following the first-order kinetics. Thus, it could be concluded that at low concentration of sodium alginate the micropellets acted as reservoir devices of frusemide which released its content depending on the concentration gradient. In spite of incorporation of Acrycoat E30D as copolymer, they could not form any drug-polymer matrix.

In the rest six batches (F4-F9), the phase I release followed first-order, except the formulations F3 and F6 which followed the zero-order release with a constant release rate over the time, independent of drug concentration in the system. On the basis of the results obtained, it could be concluded that release of frusemide from the micropellets followed a mixed kinetics, that is, initially first-order kinetics followed by zero-order kinetics. The effect of Acrycoat E30D as release rate controlling polymer was evident from the fact that with increase in the Acrycoat concentration, value of $K_{0}$ decreased in every case. At the high level of alginate this fact was more pronounced where the micropellets were found to release the active ingredients at a rate ranging $8-10 \mathrm{mg} / \mathrm{hr}$.

For all the batches of formulation the release exponent $(n)$ in an overall span of $0-9 \mathrm{hr}$ was $>1$ signifying super-Case II non-Fickian anomalous diffusion transport mechanism.

The dehydrated hydrogels generally involved the simultaneous absorption of water and desorption of drug via a swelling-controlled diffusion mechanism [17]. Similar to the transport of organic penetrant in glassy polymers, diffusion and swelling in glassy hydrogels generally would not follow 


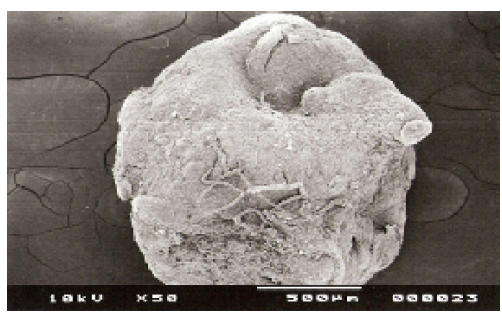

SEM photograph of frusemide micropellets (50x) formulation no. F4

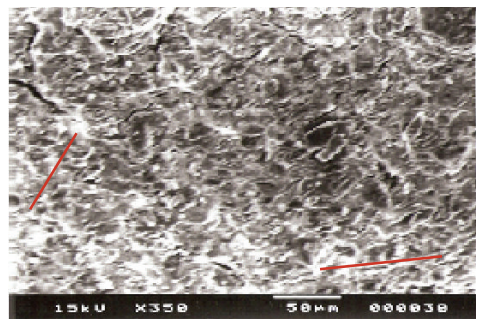

SEM photograph of frusemide micropellets $(350 \mathrm{x})$ formulation no. F7

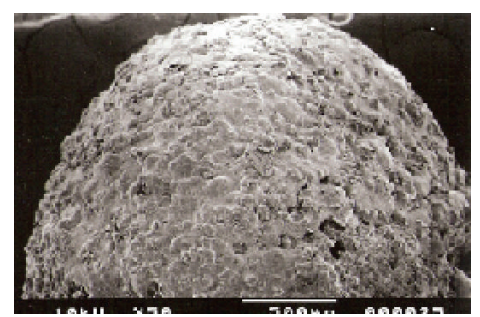

SEM photograph of frusemide micropellets (50x) formulation no. F5

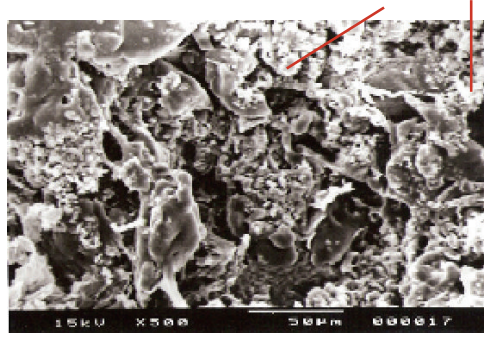

SEM photograph of dissected frusemide micropellets (500x) formulation no. F6

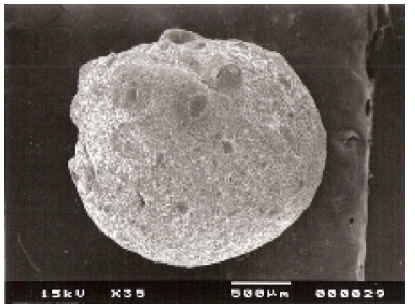

SEM photograph of frusemide micropellets $(35 \mathrm{x})$ formulation no. F7

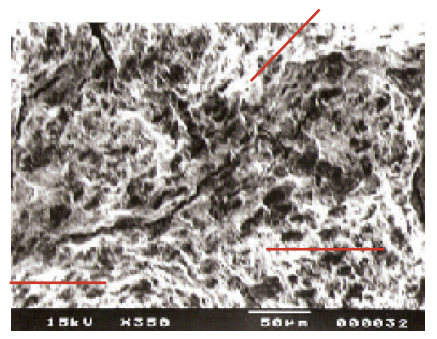

SEM photograph of frusemide micropellets $(350 \mathrm{x})$ formulation no. F8

FIGURE 5: Scanning electron micrographs of Frusemide calcium alginate micro pellets.

Dissolution profile of all nine final formulations at a glance (zero-order model)

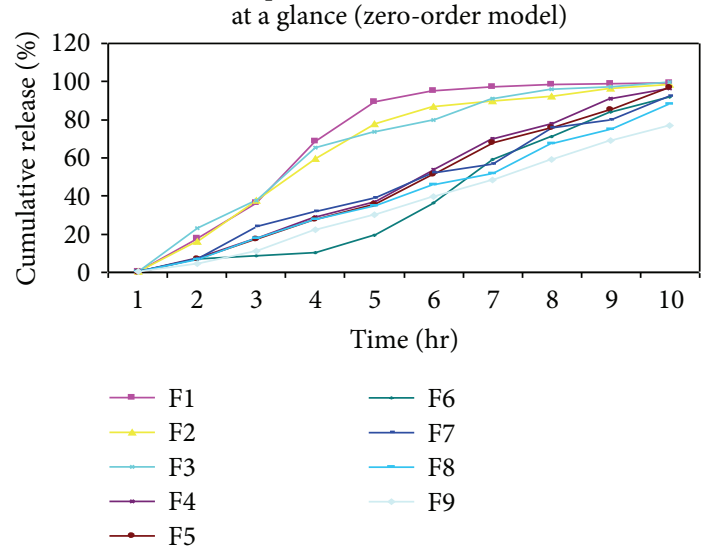

FIGURE 6: Release profile of frusemide from micropellets at different levels of sodium alginate $(-1,0,+1)$ following zero-order model.

a Fickian diffusion mechanism. The slow reorientation of polymer chains in order to accommodate the penetrating solvent molecules leads to a variety of sorption behaviours, particularly when the experimental temperatures were near or below the glass transition temperature of the hydrogel. In cases where sorption process was governed by the rate of polymer relaxation, Case II transport was followed and characterized by linear time dependence in the amount diffused and the penetrating swelling front position resulted. Generally, in most systems, the intermediate situation, termed as non-Fickian or anomalous diffusion, prevailed, whenever the rates of diffusion and polymer relaxation were comparable. On segregating the study in two phases phase I and phase II, (Table 7) this phenomenon of drug release was very much in proximity with the theory as it was seen that in the initial phase $n \gg 1$ reflecting the non-Fickian release. With time, water penetrated into the hydrogel matrix containing dispersed drug, and the polymer chains had taken up a finite amount of time to rearrange to an equilibrium state in order to accommodate the penetrating solvent. On significant hydration drug release tends to be linear with time giving $(n \sim 1)$ signifying zero-order transport mechanism.

Thus it can be concluded, that by increasing the polymer mass in the micropellets such drug delivery device could be generated which could retain a constant geometry with a constant release rate of drug following zero-order kinetic model. The reproducibility of the polymers to produce micropellets of similar release mechanism was optimized statistically.

\subsection{Optimization Data Analysis and Validation of Optimiza-} tion Model. The values of $K_{0}$ obtained under the different experimental conditions for all the nine formulations were summarized in Table 6.

The application of RSM offers, on the basis of parameter estimate, an empirical relationship between the response variable $K_{0}, X_{120}, t_{80}$, and $n$ individually and the test variables under considerations. Quadratic model (partial sum of squares-Type III) was selected for all the RSM studies. By applying multiple regression analysis on the experimental data, the response variable $K_{0}, X_{120}, t_{80}$, and $n$ and the test variables $A$ (concentration of sodium alginate $\% \mathrm{w} / \mathrm{w}$ ) and $B$ (concentration of Acrycoat E30D \% w/w) were related by second-order polynomial equations.

The graphical representation of the regression equations called the response surfaces and $3 \mathrm{D}$ curves were obtained using the software Design Expert 7.1.2 and were presented in Figure 7. 


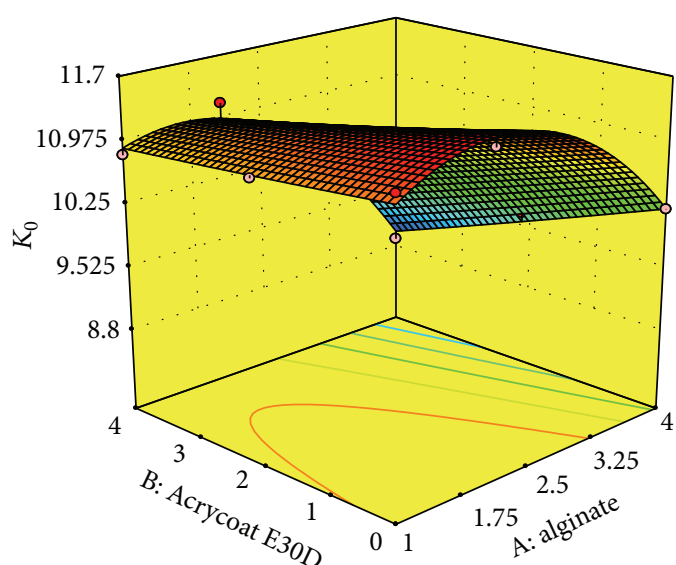

$K_{0}$

- Design points above predicted value

- Design points below predicted value

$\begin{array}{ll}11.468 & X_{1}=\text { A: alginate } \\ 8.8885 & X_{2}=\text { B: Acrycoat E30D }\end{array}$

(a) Effect of interaction between alginate and Acrycoat E30D on zero-order rate constant $\left(K_{0}\right)$ represented in $3 \mathrm{D}$ response curve

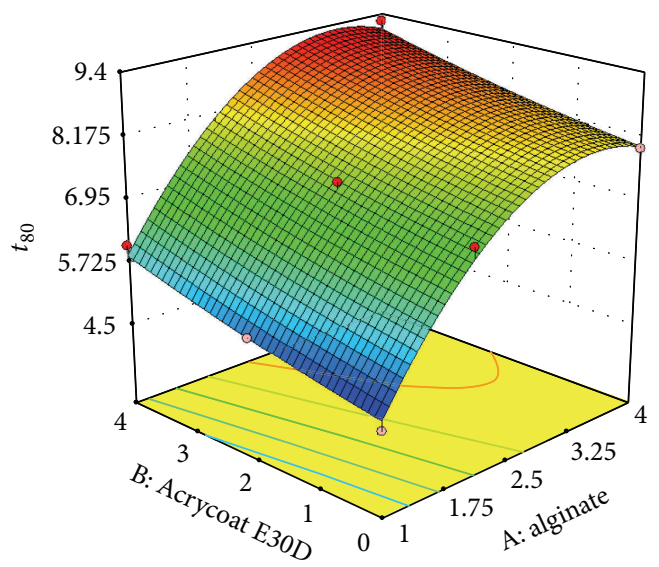

$t_{80}$
○ Design points above predicted value
○ Design points below predicted value
$\left[\begin{array}{ll}9.3 & X_{1}=\text { A: alginate } \\ 4.5 & X_{2}=\text { B: Acrycoat E30D }\end{array}\right.$

(c) Effect of interaction between alginate and Acrycoat E30D on time of $80 \%$ drug release $\left(t_{80}\right)$ represented in $3 \mathrm{D}$ response curve

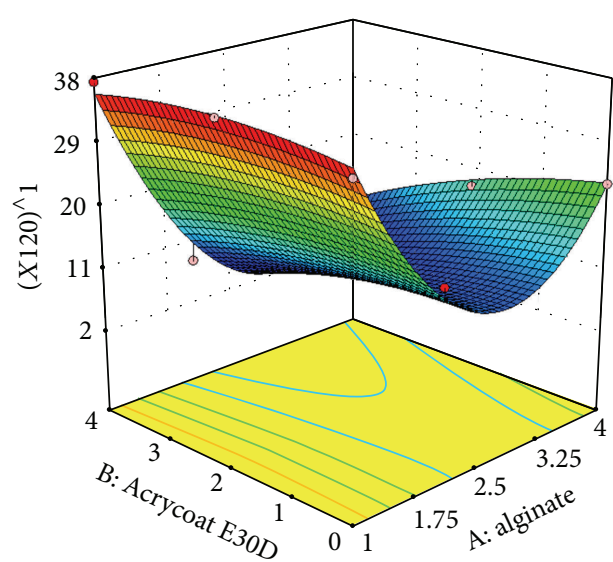

Transformed scale

$(X 120)^{\wedge} 1$

- Design points above predicted value

- Design points below predicted value

$\begin{array}{ll}37.341 & X_{1}=\text { A: alginate } \\ 8.001 & X_{2}=\text { B: Acrycoat E30D }\end{array}$

(b) Effect of interaction between alginate and Acrycoat E30D on the amount of drug released in 120 minutes $(2 \mathrm{hr}$ ) $X_{120}$, represented in $3 \mathrm{D}$ response curve

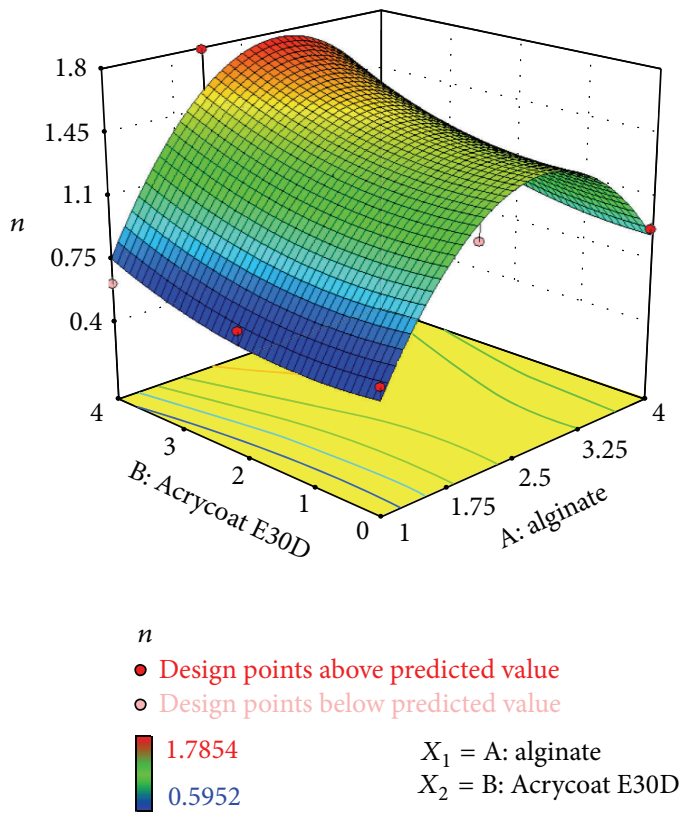

(d) Effect of interaction between alginate and Acrycoat E30D on the diffusion coefficient $(n)$ represented in 3D Response curve

FIGURE 7: Effect of interaction between alginate and Acrycoat E30D on experimental variables represented in 3D response curves.

The model equation related to zero-order release rate constant $\left(K_{0}\right)$ as response became

$$
\begin{aligned}
K_{o}= & 11.11-0.72 \times A-0.38 B-0.23 \times A \times B \\
& -0.80 \times A^{2}+9.683 E-003 \times B^{2} .
\end{aligned}
$$

A summary of the analysis of variance (ANOVA) for the selected quadratic predictive model is shown in Table 4 . Statistical testing of the model was done in the form of analysis of variance (ANOVA) which is required to test the significance and adequacy of the model. Here the ANOVA of regression model demonstrates that the model is highly significant, as evident from the calculated $F$ value (40.21) 


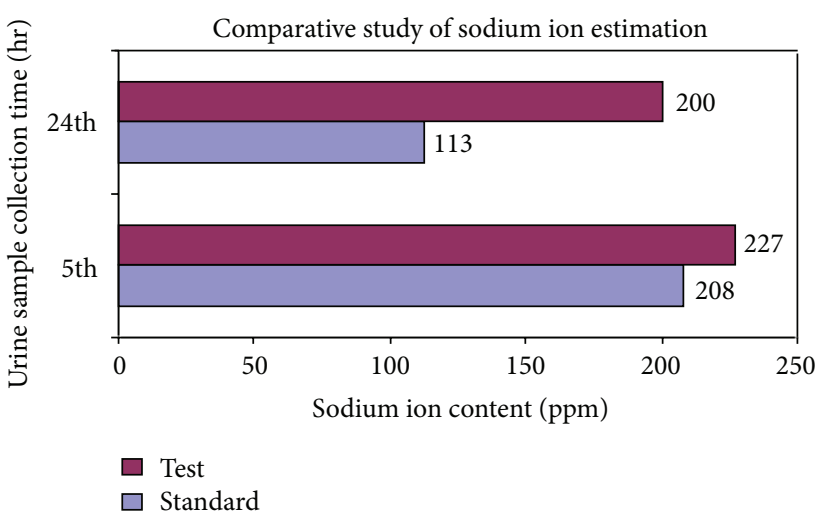

(a)

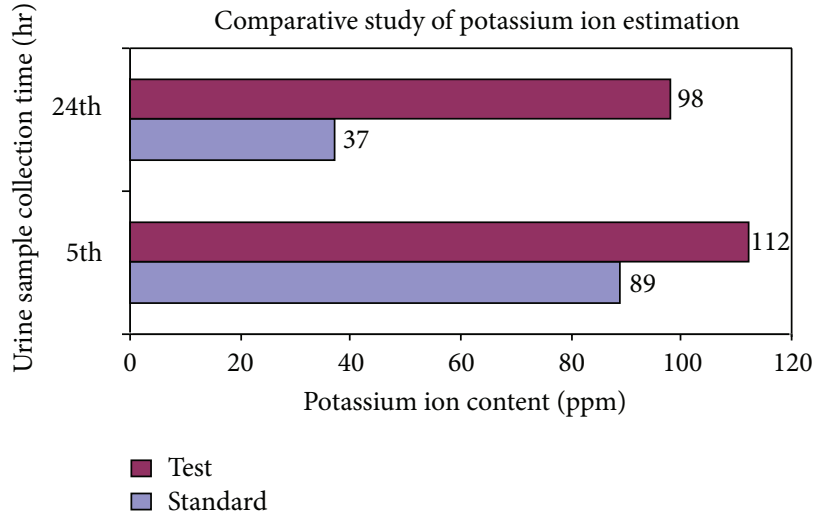

(b)

Figure 8: Comparative study of sodium ion and potassium ion estimation among test (micropellets) and standard (Lasix tablet) containing frusemide $(40 \mathrm{mg})$ in Flame Photometer.

and a very low probability value $(P<0.006)$. The model was found to be adequate for prediction within the range of the variables employed. The $P$ values are used as a tool to check the significance of each of the coefficients, which in turn may indicate the pattern of interactions between the variables. The smaller the value of $P$, the more significant the corresponding coefficient. It can be seen from Table 4 that the significant coefficients were $A(P=0.0019), B(P=0.0127)$, and $A^{2}(P=0.0105)$, the $P$ values of all of them being small at $5 \%$ confidence interval $(P<0.0500)$. The coefficients $A, B$, and $A^{2}$ had a negative effect on the zero-order release rates $\left(K_{0}\right)$ of the drug from the prepared micropellets.

The model equation related to amount of drug released in 2 hours (burst effect) $X_{120}$ as response became

$$
\begin{aligned}
X_{120}= & 9.59-9.65 \times A-3.46 \times B-3.24 \times A \times B \\
& +18.44 \times A^{2}-1.69 \times B^{2} .
\end{aligned}
$$

Here the ANOVA of regression model demonstrates that the model is highly significant, as evident from the calculated $F$ value (33.26) and a very low probability value $(P=0.0079)$. The model was found to be adequate for prediction within the range of the variables employed. It can be seen from Table 4 that the significant coefficients were $A(P=0.0024), B(P=$ $0.0424)$, and $A^{2}(P=0.0027)$ the $P$ values of all of them being small at $5 \%$ confidence interval $(P<0.0500)$. The coefficients $A, B$, and $A^{2}$ had a negative effect on the burst release $\left(X_{120}\right)$ of the drug from the prepared micropellets.

The model equation related to time required for $80 \%$ drug release $t_{80}(\mathrm{hr})$ as response became

$$
\begin{aligned}
t_{80}= & 8.17+1.65 \times A+0.58 \times B-0.027 \times A \times B \\
& -1.31 \times A^{2}+0.083 \times B^{2} .
\end{aligned}
$$

ANOVA of regression model demonstrates that the model is highly significant, as evident from the calculated $F$ value (38.12) and a very low probability value $(P=0.0065)$. The model was found to be adequate for prediction within the range of the variables employed. It can be seen from Table 4 that the significant coefficients were $A(P=0.0010), B(P=$ $0.0212)$, and $A^{2}(P=0.0145)$, the $P$ values of all of them being small at $5 \%$ confidence interval $(P<0.0500)$. The coefficients $A, B$, and $A^{2}$ had a negative effect on the time taken to release $80 \%\left(t_{80}\right)$ of the drug from the prepared micropellets.

The model equation related to Peppas diffusion coefficient $n$ as response became

$$
\begin{aligned}
n= & 1.45+0.24 \times A+0.17 \times B+0.057 \times A \times B \\
& -0.69 \times A^{2}+0.11 \times B^{2} .
\end{aligned}
$$

The ANOVA of regression model demonstrates that the model is insignificant at a confidence interval of $5 \%$, as evident from the calculated $F$ value (5.56) and a high probability value $(P=0.0943)$. The model was found to be inadequate for prediction within the range of the variables employed. It can be seen from Table 4 that the significant coefficient is $A^{2}(P=0.0232)$, the $P$ value being small at $5 \%$ confidence interval $(P<0.0500)$. The coefficients $A, B$ had no significant effect, and only the term $A^{2}$ had a statistically significant effect on the diffusion coefficient $(n)$ of the drug from the prepared micropellets.

In the research work, increased polymer level in the formulations resulted in decreased drug release rates $\left(K_{0}\right)$ and burst effect $\left(X_{120}\right)$ and increased time $\left(t_{80}\right)$ for the release of $80 \%$ of the drug from the formulated micropellets. The effect of the primary polymer, sodium alginate, was much more significant statistically $(P<0.05)$ than the copolymer Acrycoat E30D. The combined effect of both the polymer was proportional to the sole effect of sodium alginate. It could also be concluded that the concentration range within 2$4 \%(\mathrm{w} / \mathrm{w})$ of sodium alginate could give a predictive and reproductive formulation.

Though concentrations above $4 \%$ were not investigated, it could be assumed from the statistical result that no robust change in the dissolution behaviour would be achieved. On the contrary, higher concentration of polymers would 
increase the particle size and may also pose mechanical problems during extrusion technique due to high polymer viscosity.

3.11. In Vivo Evaluation of the Diuresis Followed by Optimized Formulation. The optimized formulation, that is, F9 $(4 \% \mathrm{w} / \mathrm{w}$ of both sodium alginate and Acrycoat E30D with 30\% drug load), which recorded maximum in vitro extended release of the drug over a span of 9 hour, was examined for pharmacological activity through in vivo Lipschitz test as the test has been proven to be a standard and a very useful tool for screening of potential diuretics. The Lipschitz value for both standard and test sample was found to be greater than 2.0 at the end of both 5 th and 24 th hours (Table 10), confirming the positive diuretic effect of both samples. But at the end of the 24th hour, test sample showed significantly $(P<0.05)$ high quotient (7.02) implying high volume of urine being excreted on using the micropellets when compared to the standard tablets (4.63). It also proves the efficacy of the formulation in providing therapeutic effect to the subject. This is further supported by the increase in percentage of volume of urine collected compared to the control group. Though at the end of the 5th hour both standard and test sample showed similar increment (300 and 362.5\%) at the end of 24th hour test sample again showed significantly $(P<0.05)$ high increment, $602.1 \%$, whereas the standard showed an increment value of $444.5 \%$. This establishes the fact that the test formulation was successful in sustaining the diuretic effect of the drug till 24 hours. Thus the objective of the research work was partly met from these data.

\section{Conclusion}

One of the primary objectives of the research work was to achieve controlled release micro particulate drug delivery systems in the form of micropellets through the use of a combination of water-soluble polymer such as sodium alginate and a water-insoluble polymer Acrycoat E30D. In the research work, increased polymer level in the formulations resulted in decreased drug release rates $\left(K_{0}\right)$ and burst effect $\left(X_{120}\right)$ and increased time $\left(t_{80}\right)$ for the release of $80 \%$ of the drug from the formulated micropellets. The effect of the primary polymer, sodium alginate, was much more significant statistically $(P<0.05)$ than the copolymer Acrycoat E30D. The combined effect was proportional to the sole effect of sodium alginate. All other pharmacokinetic parameters remained fairly unchanged with its incorporation, and by increasing the polymer mass in the micropellets such drug delivery device could be generated which can retain a constant geometry with a constant release rate of drug following zero-order kinetic models. It could also be concluded that the concentration range within $2-4 \%(\mathrm{w} / \mathrm{w})$ of sodium alginate could give a predictive and reproductive formulation. On the contrary, higher concentration of polymers would increase the particle size and may also pose mechanical problems during extrusion technique due to high polymer viscosity. The in vivo study acclaimed that calcium alginate micropellets of frusemide can produce a much greater diuretic effect over an extended period of 24 hours. Hence a single dose of the formulation is sufficient in the management of peripheral edema and ascites in congestive heart failure and as well in the treatment of chronic hypertension, leading to better patient compliance.

\section{Conflict of Interests}

There is no conflict of interests.

\section{Acknowledgments}

The authors are thankful to Aventis Pharma Ltd. (Ankleshwar, India) for providing gift sample of frusemide and to Corel Pharma (Ahmedabad, India) for their generous gift sample of Acrycoat E30D. The authors are also thankful to Department of Metallurgy, Jadavpur University, Kolkata, India, for providing SEM facility.

\section{References}

[1] D. C. Montgomery, "Response surface methodology," in Design and Analysis of Experiments, D. C. Montgomery, Ed., John Wiley \& Sons, New York, NY, USA, 4th edition, 1996.

[2] B. Singh and N. Ahuja, "Response surface optimization of drug delivery system," in Progress in Controlled and Novel Drug Delivery Systems, N. K. Jain, Ed., CBS Publishers \& Distributors, New Delhi, India, 2004.

[3] B. Singh, M. Dahiya, V. Saharan, and N. Ahuja, "Optimizing drug delivery systems using systematic "design of experiments"-part II: retrospect and prospects," Critical Reviews in Therapeutic Drug Carrier Systems, vol. 22, no. 3, pp. 215-294, 2005.

[4] B. Singh, R. Kumar, and N. Ahuja, "Optimizing drug delivery systems using systematic "design of experiments"-part I: fundamental aspects," Critical Reviews in Therapeutic Drug Carrier Systems, vol. 22, no. 1, pp. 27-105, 2005.

[5] B. Singh, G. Mehta, R. Kumar, A. Bhatia, N. Ahuja, and O. P. Katare, "Design, development and optimization of nimesulideloaded liposomal systems for topical application," Current Drug Delivery, vol. 2, no. 2, pp. 143-153, 2005.

[6] B. Singh, S. K. Chakkal, and N. Ahuja, "Formulation and optimization of controlled release mucoadhesive tablets of atenolol using response surface methodology," AAPS PharmSciTech, vol. 7, no. 1, pp. E19-E28, 2006.

[7] A. Ghosh, L. K. Nath, B. K. Dey, and P. Roy, "A study on the effect of different polymers on frusemide loaded calcium alginate micro pellets prepared by ionotropic gelation technique," Indian Journal of Pharmaceutical Education and Research, vol. 41, no. 4, pp. 329-336, 2007.

[8] N. A. Peppas, "Analysis of Fickian and non-Fickian drug release from polymers," Pharmaceutica Acta Helvetiae, vol. 60, no. 4, pp. 110-111, 1985.

[9] Indian Pharmacopoeia, vol. 1-2, The Controller of Publication, New Delhi, India, 1996.

[10] L. Lachman, H. A. Lieberman, and J. K. Kanig, The Theory and Practice of Industrial Pharmacy, Lea \& Febiger, Philadelphia, $\mathrm{Pa}$, USA, 3rd edition, 1991.

[11] R. Bodmeier and O. Paeratakul, "Spherical agglomerates of water-insoluble drugs," Journal of Pharmaceutical Sciences, vol. 78, no. 11, pp. 964-967, 1989. 
[12] K. Abu-Izza, L. Garcia-Contreras, and D. R. Lu, "Preparation and evaluation of zidovudine-loaded sustained-release microspheres. 2. Optimization of multiple response variables," Journal of Pharmaceutical Sciences, vol. 85, no. 6, pp. 572-576, 1996.

[13] British Pharmacopoeia, vol. 1, British Pharmacopoeia Commission, London, UK, 2003.

[14] P. D. Shethi, HPLC-Quantitative Analysis of Pharmaceutical Formulations, vol. 2, 2007.

[15] W. L. Lipschitz, Z. Hadidian, and A. Kerpcser, "Bioassay of diuretics," Journal of Pharmacology and Experimental Therapeutics, vol. 79, pp. 97-110, 1943.

[16] H. G. Vogel, W. H. Vogel, B. A. Schölkens, J. Sandow, G. Müller, and W. F. Vogel, Drug Discovery and Evaluations, Springer, Berlin, Germany, 2nd edition, 2002.

[17] P. Costa and J. M. S. Lobo, "Modeling and comparison of dissolution profiles," European Journal of Pharmaceutical Sciences, vol. 13, no. 2, pp. 123-133, 2001. 

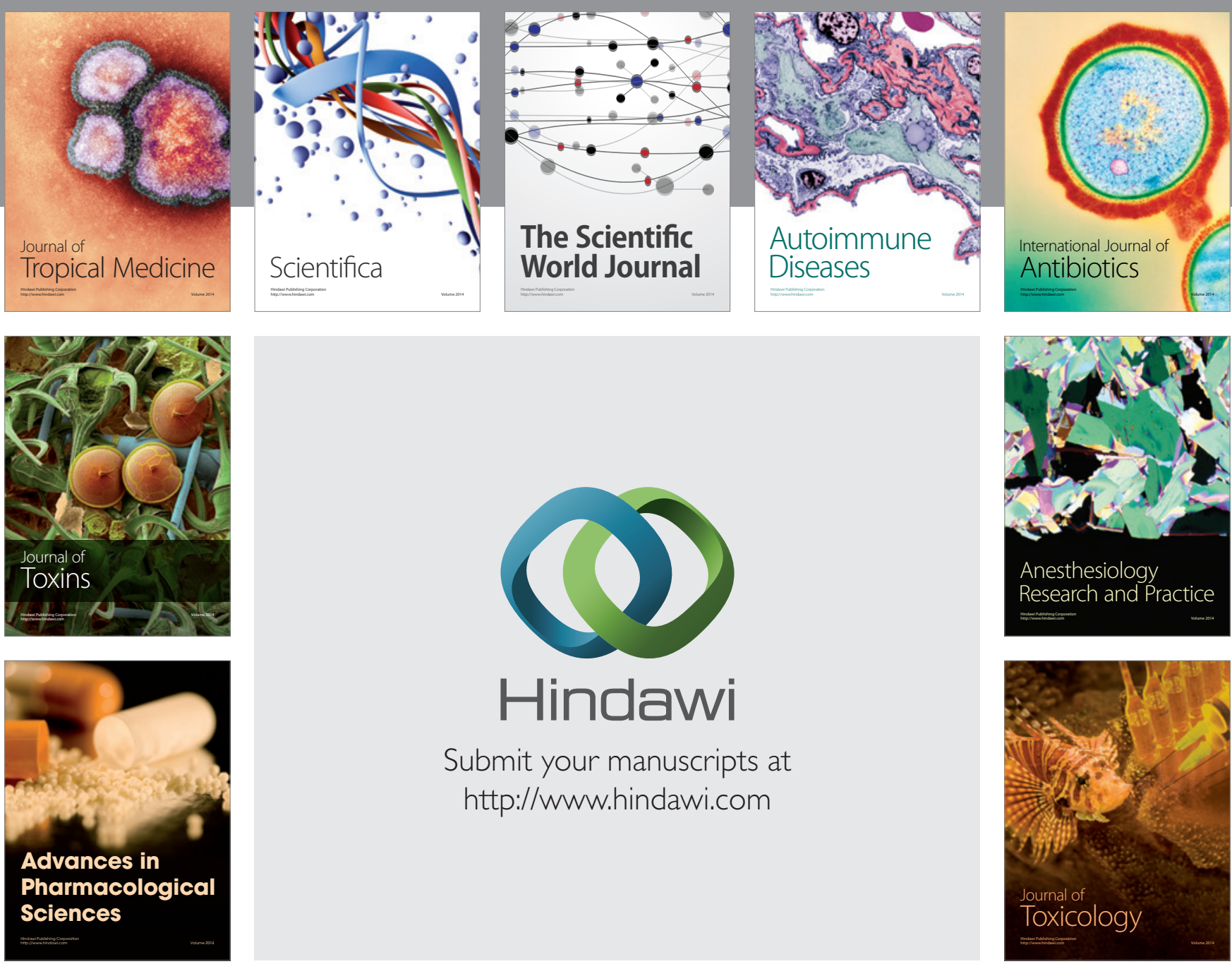

\section{Hindawi}

Submit your manuscripts at

http://www.hindawi.com
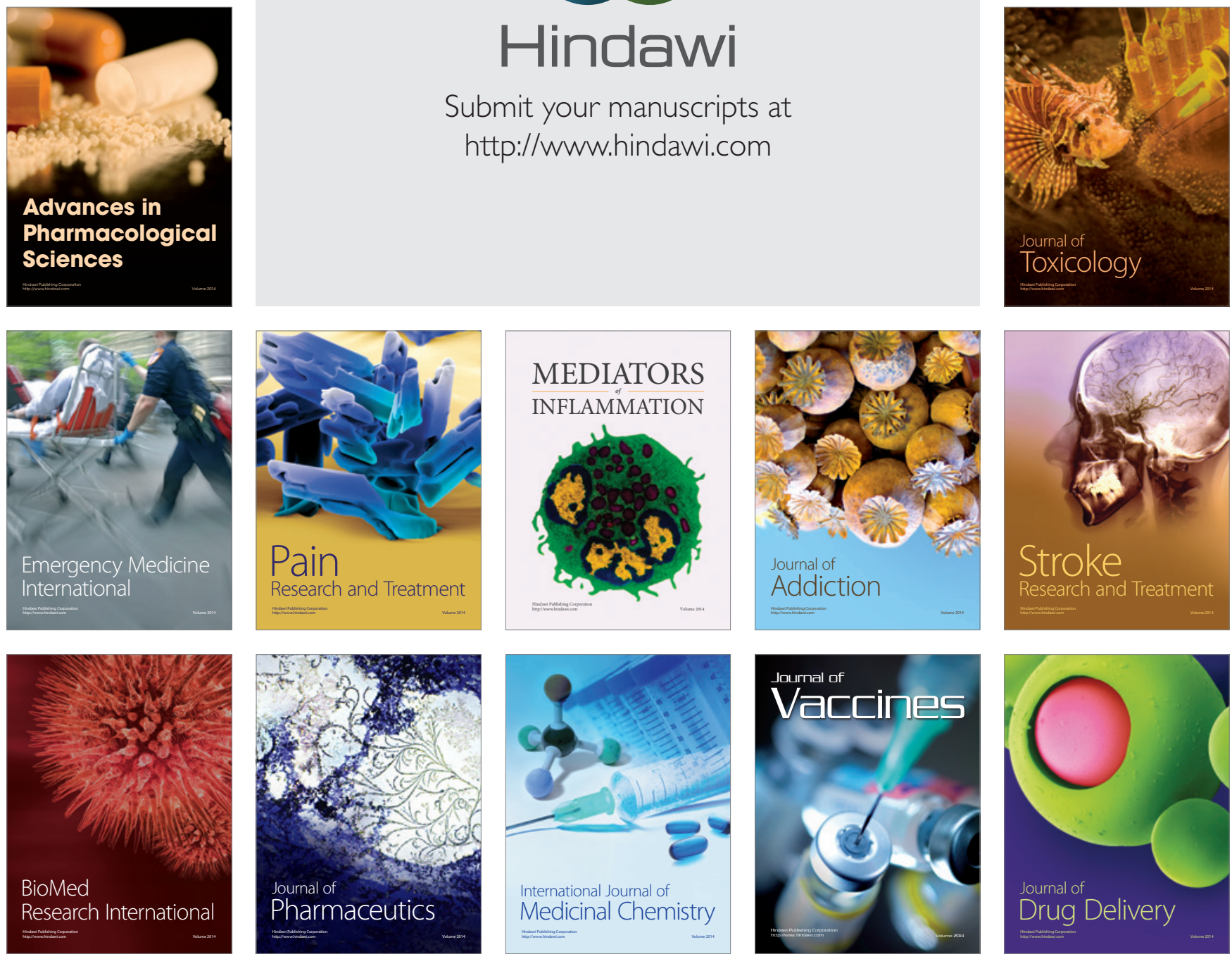